\title{
Effect of Delayed Cord Clamping at 30 Seconds and I Minute on Neonatal Hematocrit in Term Cesarean Delivery: A Randomized Trial
}

This article was published in the following Dove Press journal: International Journal of Women's Health

\author{
Metha Songthamwat (D) \\ Patthamon Witsawapaisan' \\ Sopida Tanthawat ${ }^{2}$ \\ Srisuda Songthamwat' \\ 'Department of Obstetrics and \\ Gynecology, Udonthani Hospital, \\ Udonthani, Thailand; ${ }^{2}$ Department of \\ Pediatrics, Udonthani Hospital, \\ Udonthani, Thailand
}

Objective: To compare the effect of delayed cord clamping at 30 seconds and 1 minute on the incidence of neonatal hematocrit, anemia, maternal and neonatal complications in term cesarean delivered neonates.

Methods: An opened labelled, randomized controlled trial was undertaken. The 160 healthy term cesarean-born neonates were randomly allocated to either 30 seconds or 1-minute groups of delayed cord clamping (DCC) (groups 1 and 2). Neonatal venous hematocrit (Hct) and microbilirubin (Mb) were measured at 48-72 hours after birth.

Results: One hundred and fifty-nine neonates completed this study. Mean neonatal hematocrit \pm standard deviation at $48-72$ hours was $49.9 \pm 6.0 \%$ in group 1 and $51.2 \pm 5.9 \%$ in group 2 without a statistical difference. Neonatal anemia (Hct less than $45 \%$ ) occurred in 14 / 79 neonates $(17.7 \%)$ in group 1 and in $8 / 80$ cases $(10.0 \%)$ in group 2 without a significant difference between groups. The incidence of neonatal jaundice and polycythemia (hematocrit more than $65 \%$ ) was similar between groups. There were no significant differences; in the estimated blood loss during the operation, the incidence of postpartum hemorrhage and other maternal and neonatal complications.

Conclusion: Neonatal hematocrit was not significantly different following DCC at 30 seconds and at 1 minute, but the incidence of neonatal anemia decreased with the longer timing of DCC. The estimated blood loss and other complications were not different between the two groups. Therefore, one minute-DCC should be considered for neonatal anemic prevention when compared with 30 seconds-DCC.

Keywords: delayed cord clamping, timing, hematocrit, neonatal anemia

\section{Introduction}

Neonatal anemia is an important problem that has multiple sequelae to long-term neurology, emotion, and behavior development of newborns. ${ }^{1,2}$ These symptoms and sequelae can persist for more than 10 years, even if treatment was received. ${ }^{3}$ Blood in the umbilical cord can be used as an autotransfusion to the neonate. Delayed cord clamping (DCC) can protect against neonatal anemia in neonates by transferring residual blood in the placenta. This practice is easy, effective and without cost. ${ }^{4,5}$

Many research studies and recommendations have supported DCC's advantages for both vaginal and cesarean delivery. ${ }^{5-8}$ The proper exact time for DCC varies between authorities; for example, the World Health Organization (2012) recommends DCC at 1-3 minute, ${ }^{9}$ the American College of Obstetricians and Gynecologists
Correspondence: Metha Songthamwat Department of Obstetrics and Gynecology, Udonthani Hospital, Udonthani 41000, Thailand Email udonhome@yahoo.com 
(ACOG) recommends DCC at 30-60 seconds, ${ }^{4}$ the National Institute for Health and Care Excellence (NICE) recommends DCC at 1-5 minutes or longer if the mother request. $^{10}$

Cesarean delivery is different from vaginal delivery. The different timing of DCC is important for mothers and neonates. A longer time for DCC may correlate with blood loss, neonatal jaundice, and polycythemia. Similarly, a shorter time for DCC may cause neonatal anemia. ${ }^{5}$ The goal of this research study was to evaluate the appropriate time of either 30 seconds or 1 minute for anemic prevention in cesarean delivered neonates.

\section{Materials and Methods}

This study was a randomized controlled trial conducted in the Department of Obstetrics and Gynecology, Udonthani Hospital, Udonthani, Thailand. It was conducted according to the Declaration of Helsinki, and national laws and regulations about clinical studies. The study protocol was approved by the Udonthani Hospital Research Ethics Committee (number 38/2561) and was registered in the Thailand Clinical Trial Registry (TCTR 20181008006). The study's participants were 160 pregnant women who underwent cesarean delivery between October 2018 and November 2019. They were counseled and invited to participate in this study.

The inclusion criteria were singleton pregnancies, age 20 years or older, who delivered by elective cesarean section between 37 and 41 weeks gestation. The exclusion criteria were pregnancy with severe medical complication, fetal anomaly, fetal growth restriction, heavy bleeding immediately after birth, or were unwilling to participate in this study. The exclusion criteria included infants with signs of birth asphyxia according to the obstetrician's judgement, such as non-vigorous infant.

A written informed consent was obtained after the explanation of the study to the participants. Then, all participants were randomly allocated to one of the two study groups. The block randomization, by a block of 4 using computer-generated numbers and sealed opaque envelopes, was performed.

The indication for cesarean delivery was according to the hospital's protocol. A preoperative blood test was done including hematocrit (Hct) and hemoglobin concentration $(\mathrm{Hb})$. All cases received a prophylactic antibiotic using either cefazolin or cefoxitin.

The anesthesia technique was spinal anesthesia which was performed by an anesthesiologist in the operating room using $0.5 \%$ bupivacaine plus $0.1-0.2 \mathrm{mg}$ of morphine. Then, all participants underwent low transverse cesarean section. All patients received standard care for low transverse caesarean section in the operating room, recovery room and were transferred to the postpartum ward after 2 hours post-operation.

During the operation, after delivering the infant, the research nurse announced to the obstetrician when 30 seconds had passed in group 1 and 1 minute in group 2 according to randomized group; then, the umbilical cord was clamped. During the waiting time for DCC, the baby was placed on the maternal thigh, bleeding at the uterine incision was checked and clamped. After cord clamping, the placental was delivered, intravenous oxytocin was given, the incisional wound was sutured and routine newborn care was done. ${ }^{8,11}$ Blood loss during delivery was measured using visual estimation by consensus between the anesthetic and surgical nurses.

Maternal and neonatal complications, Apgar scores and birth weight were recorded. The newborn Hct and microbilirubin $(\mathrm{Mb})$ were measured using venous blood at 48-72 hours after delivery. Complete blood count was analyzed by an automated hematology analyzer (Sysmex $\mathrm{XN}-3000$, Meditop Company). Mb was analyzed by an automated hematology analyzer (MB NEO-BIL Plus, Zenith Science Company). Neonatal Hct was measured using a hematocrit centrifuge and a hematocrit reader.

Neonatal anemia was defined as when neonatal Hct was less than $45 \%$, and neonatal polycythemia was when Hct was more than $65 \%$. ${ }^{7,12}$ Clinical neonatal jaundice was defined by the pediatricians using $\mathrm{Mb}$ level of more than the standard curve value graph ${ }^{13}$ and their clinical judgement. Anemia in the mother was defined as when maternal Hct was less than $33 \%$.

The mean neonatal Hct and prevalence of neonatal anemia at 48 hours in group 1 and 2 were compared. Neonatal polycythemia, jaundice and other neonatal complications were compared between the two groups. Estimated maternal blood loss at delivery and maternal complication between groups were also analyzed.

\section{Statistical Analysis}

The sample size was calculated using the formula for randomized controlled trial for binary data. ${ }^{14}$ The proportion of neonatal anemia at 30 seconds of DCC was 0.15 and 0.13 difference between groups were used for calculation. ${ }^{12} \mathrm{~A} \alpha$ was 0.05 and the power was $80 \%$. The calculated sample size was 72 participants in each group. 
An estimated drop-out rate of $10 \%$ was added and a total number of 160 participants, with 80 per group, was used.

The participants' characteristics are presented as number, percentage, range or mean \pm standard deviation. The groups were compared using a linear regression analysis for continuous variables. Logistic regression analysis was used for categorical variables. The mean difference, proportion difference with a $95 \%$ confidence interval were calculated for the magnitude of effect. Data were analyzed as per-protocol method. Statistical analysis was performed using Stata version13. A P-value $<0.05$ was considered statistically significant.

\section{Results}

This study included 160 participants who were randomly allocated with 80 participants per group which were DCC at 30-seconds group (group1) and DCC at 1-minute group (group 2). After the study was complete, one participant in group 1 was excluded due to non-vigorous baby (no breathing or crying). A consort diagram is presented in Figure 1. The maternal baseline characteristics of each group are shown in Table 1. All groups were comparable in terms of gravida, parity, gestational age, maternal age, maternal Hct and anemia, except maternal body mass index.

The mean operative time was comparable in both groups (range 23-110 minutes) and mean estimated intraoperative blood loss was 274.7 and $272.5 \mathrm{~mL}$ in group 1 and group 2, respectively, (range 100-800 $\mathrm{mL}$ ) without statistically significant difference between the groups. Placenta weight and cord length were also similar in both groups.

At 48-72 hours after birth, blood sampling was done on 79 and 80 babies in groups 1 and 2, respectively. Mean venous Hct values were $49.9 \pm 6.0 \%$ in group 1 (range 37-63), and $51.2 \pm 5.9 \%$ in group 2 (range $40-65$ ) without any statistically significant difference. Neonatal anemia (Hct less than 45\%) was detected in 14/79 cases (17.7\%) in group 1 and 8/80 cases $(10.0 \%)$ in group 2 and there were no statistically significant differences between groups (Table 2). Neonatal polycythemia

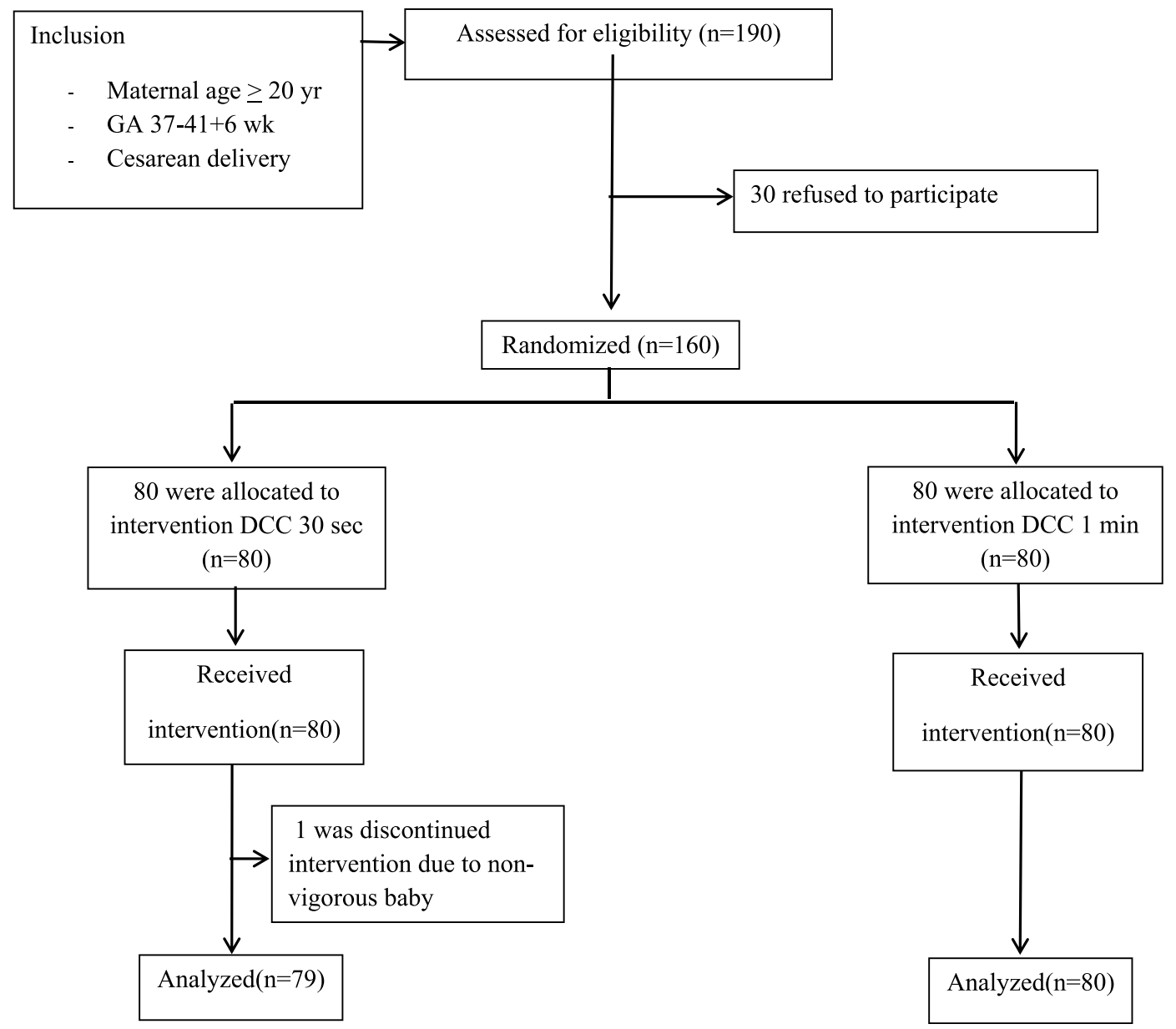

Figure I Consort diagram. 
Table I Comparison of Maternal Characteristics Between Groups

\begin{tabular}{|c|c|c|c|}
\hline Characteristics & DCC $30 \sec (n=79)$ & $D C C I \min (n=80)$ & P value ${ }^{\beta}$ \\
\hline Maternal age $(y r)$, mean $\pm S D$ & $28.6 \pm 5.2$ & $29.0 \pm 5.6$ & 0.625 \\
\hline Gravida, mean $\pm S D$ & $2.2 \pm 1.0$ & $2.1 \pm 0.7$ & 0.578 \\
\hline Nulliparity, n (\%) & $23(29.1 \%)$ & $16(20.0 \%)$ & 0.299 \\
\hline Gestational Age (wk), mean $\pm S D$ & $38.9 \pm 1.1$ & $38.8 \pm 1.2$ & 0.304 \\
\hline BMI $\left(\mathrm{kg} / \mathrm{m}^{2}\right)$, mean $\pm S D$ & $27.9 \pm 3.8$ & $29.5 \pm 5.1$ & $0.03 *$ \\
\hline Maternal Hct (\%), n (\%) & $35.5 \pm 3.1$ & $35.3 \pm 3.3$ & 0.700 \\
\hline Anemia & $6(7.8 \%)$ & $5(6.3 \%)$ & 0.738 \\
\hline Operation time (min), mean \pm SD & $49.2 \pm 15.7$ & $49.5 \pm 26.8$ & 0.940 \\
\hline Cord length $(\mathrm{cm})$, mean $\pm S D$ & $47.6 \pm 7.3$ & $48.5 \pm 6.7$ & 0.418 \\
\hline Placental weight $(\mathrm{gm})$, mean $\pm S D$ & $551.3 \pm 102.8$ & $569.4 \pm 109.8$ & 0.283 \\
\hline
\end{tabular}

Notes: ${ }^{\beta} \mathrm{P}$ value was calculated by linear regression analysis for continuous outcome and by binary regression for binary outcome. ${ }^{*}$ Statistically significant difference $(\mathrm{P}$ value $<0.05)$.

Abbreviations: DCC, delayed cord clamping; BMI, body mass index; Hct, hematocrit; yr, year; wk, week; SD, standard deviation.

Table 2 Comparison of Primary and Secondary Outcomes Between Groups

\begin{tabular}{|c|c|c|c|c|}
\hline Characteristics & $\begin{array}{l}\text { DCC } 30 \sec (\text { Group I) } \\
(n=79)\end{array}$ & $\begin{array}{l}\text { DCC I min (Group 2) } \\
(n=80)\end{array}$ & $\begin{array}{l}\text { Difference Between Group } \\
2-\mathrm{I}(95 \% \mathrm{Cl})\end{array}$ & P value* \\
\hline Neonatal Hct at $48-72 \mathrm{hr}(\%)$, mean \pm SD & $49.9 \pm 6.0$ & $51.2 \pm 5.9$ & $-1.3(-3.16$ to 0.56$)$ & 0.169 \\
\hline Neonatal anemia $\mathrm{n}(\%)$ & $14(17.7 \%)$ & $8(10.0 \%)$ & $-7.7 \%(-18.4$ to 3.0$)$ & 0.159 \\
\hline Polycythemia n (\%) & $0(0)$ & $0(0)$ & NA & NA \\
\hline $\mathrm{Mb}$ at $48-72 \mathrm{hr}$, mean $\pm \mathrm{SD}$ & $9.4 \pm 1.9$ & $9.2 \pm 2.3$ & $0.13(-0.52$ to 0.79$)$ & 0.692 \\
\hline Clinical jaundice, n (\%) & $19(24.1 \%)$ & $17(21.3 \%)$ & $-2.8 \%(-15.8$ to 10.2$)$ & 0.673 \\
\hline Phototherapy n (\%) & $15(19.0 \%)$ & II (13.8\%) & $-5.2 \%(-16.7$ to 6.2$)$ & 0.372 \\
\hline Estimate blood loss $(\mathrm{mL})$, mean $\pm \mathrm{SD}$ & $274.7 \pm 110.3$ & $272.5 \pm 97.1$ & $2.2(-30.4$ to 34.7$)$ & 0.895 \\
\hline
\end{tabular}

Note: *P value was calculated by linear regression analysis for continuous outcome and by binary regression for binary outcome. Abbreviations: DCC, delay clamp cord; Cl, confidence interval; SD, standard deviation; Hct, hematocrit; Mb, microbilirubin.

was not found in both groups. Clinical neonatal jaundice was founded in 19 cases (24.1\%) in group 1 and 17 cases $(21.3 \%)$ in group 2 which was not statistically significant difference (range $\mathrm{Mb}$ in all cases was 3.2-18.1). Phototherapy was done in 15 cases (19.0\%) in group 1 and 11 cases $(13.8 \%)$ in group 2 which was similar between groups. Respiratory complications, such as respiratory distress syndrome, transient tachypnea of the newborn, and pneumonia, were similar between groups (Table 3).

The mean neonatal birthweight was 3168.8 gram (range 2250-4220) with 4 (2.5\%) low birthweight babies (less than 2500 gram). The neonatal length and head circumference were also comparable between groups. Neonatal Apgar scores at 1,5 and 10 minutes were not different between the groups (Table 3 ).

\section{Discussion}

DCC has been advised by many guidelines from around the world (WHO, ACOG, and NICE) ${ }^{4,8,10}$ with many studies supporting DCC's advantage in reducing anemia in neonates. ${ }^{9,15-20}$ A randomized study by Purisch et al, ${ }^{21}$ compared immediate cord clamping (within 15 seconds after birth) with DCC (60 seconds after birth) in cesarean delivery. This study demonstrated that mean neonatal hemoglobin level was higher in the DCC group $(18.1 \mathrm{~g} / \mathrm{dl}$ vs $16.4 \mathrm{~g} / \mathrm{dl})$. However, the recommended timing of DCC in cesarean delivery is still problematic. Delayed cord clamping time in vaginal delivery can vary between 30 seconds, to more than 1 minute, or as long as the mother request but there is no definite DCC time recommended in cesarean delivery. ${ }^{4,8,10}$

During cesarean delivery, the DCC time is important for both mother and baby. Too short of a time of DCC may increase the risk of neonatal anemia, and too long of a time delays the uterine incision suturing and neonatal care. This study compared the effect of DCC at 30 seconds and 1 minute for reducing neonatal anemia. It also compared the potential for undesirable side effects of DCC such as surgical bleeding, neonatal jaundice, or polycythemia. The results demonstrate that no statistically significant difference in mean neonatal hematocrit between the groups. The incidence 
Table 3 Comparison of Neonatal Outcomes Between Groups

\begin{tabular}{|c|c|c|c|}
\hline Characteristics & DCC $30 \sec (n=79)$ & $D C C I \min (n=80)$ & P value* \\
\hline Newborn birthweight $(\mathrm{kg})$, mean \pm SD & $3124.9 \pm 359.3$ & $3212.7 \pm 395.9$ & 0.146 \\
\hline Newborn length $(\mathrm{cm})$, mean $\pm S D$ & $50.5 \pm 1.8$ & $50.2 \pm 2.3$ & 0.505 \\
\hline Newborn HC, mean $\pm S D$ & $33.5 \pm 1.2$ & $33.6 \pm 2.9$ & 0.709 \\
\hline Apgar I min, mean \pm SD & $9.1 \pm 0.5$ & $9.1 \pm 0.6$ & 0.654 \\
\hline Apgar 5 min, mean $\pm S D$ & $10.0 \pm 0.2$ & $9.9 \pm 0.3$ & 0.154 \\
\hline Apgar $10 \mathrm{~min}$, mean $\pm S D$ & $10.0 \pm 0.2$ & $10.0 \pm 0.2$ & 0.413 \\
\hline Respiratory complication, n (\%) & $3(3.8 \%)$ & $\mathrm{I}(\mathrm{I} .3 \%)$ & 0.305 \\
\hline NICU admission, $\mathrm{n}(\%)$ & $\mathrm{I}(\mathrm{I} .3)$ & $0(0)$ & NA \\
\hline
\end{tabular}

Notes: *P value was calculated by linear regression analysis for continuous outcome and by binary regression for binary outcome. Respiratory complications included respiratory distress syndrome, pneumonia and transient tachypnea of the newborn.

Abbreviations: SD, standard deviation; DCC, delay clamp cord; HC, head circumference; NICU, neonatal intensive care unit.

of neonatal anemia was $10.0 \%$ in 30 seconds versus $17.7 \%$ in 1 minute DCC without a significant difference.

The benefit of DCC comes from an increase in the transference time of residual blood in the placenta to the neonate. There are disadvantages such as increased waiting time before the cesarean incision wound is sutured, this may increase blood loss. Blood loss during cesarean delivery in this study was similar in both groups. This is also similar to Purisch et al study ${ }^{21}$ that compared postoperative maternal hemoglobin between early cord clamping and DCC group. The mean neonatal blood concentration after DCC in this study was similar to a Thai report ${ }^{22}$ but was lower than other western reports which the mean neonatal hematocrit of DCC infants at $24-48$ hours was $55.8 \pm 5.1 \%{ }^{7}$ and mean hemoglobin was $18.5-18.9 \mathrm{~g} / \mathrm{dl}^{18,23}$

The incidence of neonatal anemia after DCC at 30 seconds in this study $(17.7 \%)$ was comparable to early cord clamping in a previous study which reported $16.8 \%$ of neonates with neonatal anemia at 24-48 hours after early cord clamping. ${ }^{12}$ This study's incidence of anemia in DCC at 1 minute $(10.0 \%)$ was higher than a previous report which was $2.3 \%$ and $3.3 \%$ at 1 minute and 3 minutes DCC, respectively. ${ }^{12}$ Performing DCC for greater than 1 minute during cesarean delivery needs additional studies to evaluate its advantage and complication.

DCC can also delay the process of newborn care including temperature care. Another worrisome complication is the increasing unnecessary blood volume to the newborn. This additional blood could lead to polycythemia, and jaundice when compared with early cord clamping. ${ }^{7}$ However, this study found no significant difference in adverse neonatal effects, such as polycythemia, jaundice, or respiratory complication, in either DCC group. Therefore, our suggestion is prolonged DCC for at least one minute during cesarean delivery which is compatible with some prior recommendations. ${ }^{5,8}$

The incidence of neonatal jaundice in this study was higher than a previous study which reported clinical jaundice in $11.5 \%$ of DCC babies and $9.9 \%$ of early cord clamping babies. ${ }^{7}$ Therefore, close observation of neonatal jaundice is recommended in DCC babies. Most jaundice cases in this study were mild jaundice and all responded to the phototherapy treatment without complication.

The strength of this study is the study's design is a prospective randomized controlled trial. The limitations of this study are; first, the outcome of this study was only the short-term effect (the neonatal Hct at 48-72 hours); however, the main advantage of DCC in a term infant is the higher iron stores at 6 months of age ${ }^{7}$ especially in a low iron intake area such as North-east, Thailand. Long-term study is still needed to determine the proper time of DCC effect to the infant at 6 months or older. Second, the estimation of intraoperative blood loss was done by visual estimation, so the accuracy was limited. Third, the sample size was not large enough to detect clinical assessment of safety.

\section{Conclusion}

Neonatal hematocrit was not significantly different following DCC; at 30 seconds and at 1 minute but, the incidence of neonatal anemia decreased with the longer timing of DCC. The estimated blood loss and other complications were not different between the two groups. Therefore, one minute-DCC should be considered for neonatal anemic prevention when compared with 30 seconds DCC.

\section{Data Sharing Statement}

All available anonymized data can be obtained by contacting the corresponding author (Dr. Metha 
Songthamwat, e-mail:udonhome@yahoo.com) until 5 years after publication.

\section{Ethics Statement}

The study protocol was approved by the Udonthani Research Ethics Committee: Number 38/2561. The study protocol was registered in the Thailand Clinical trial Registry: Number TCTR 20181008006.

\section{Acknowledgments}

We gratefully acknowledge Dr. Narong Tadadet director of Udonthani Hospital for permission and grant support. Thanks for Udonthani Hospital staff and all participants who participated in this trial.

\section{Disclosure}

The authors report no conflicts of interest in this work.

\section{References}

1. Grantham-McGregor S, Ani C. A review of studies on the effect of iron deficiency on cognitive development in children. J Nutr. 2001;131 (2):649S-66S; discussion 66S-68S. doi:10.1093/jn/131.2.649S

2. Lozoff B, Georgieff MK. Iron deficiency and brain development. Semin Pediatr Neurol. 2006;13(3):158-165. doi:10.1016/j.spen.2006. 08.004

3. Lozoff B, Jimenez E, Hagen J, Mollen E, Wolf AW. Poorer behavioral and developmental outcome more than 10 years after treatment for iron deficiency in infancy. Pediatrics. 2000;105(4):e59. doi:10.1542/ peds.105.4.e51

4. Committee on Obstetric Practice. Committee Opinion No. 684: delayed Umbilical Cord Clamping After Birth. Obstet Gynecol. 2017;129(1):e5-e10. doi:10.1097/AOG.0000000000001860

5. Funai EF. Management of normal labor and delivery. In: UpToDate, Lockwood CJ (ed), UpToDate UpTodate, Waltham, MA, 2019.

6. Hutton EK, Hassan ES. Late vs early clamping of the umbilical cord in full-term neonates: systematic review and meta-analysis of controlled trials. JAMA. 2007;297(11):1241-1252. doi:10.1001/jama.297.11.1241

7. McDonald SJ, Middleton P, Dowswell T, Morris PS. Effect of timing of umbilical cord clamping of term infants on maternal and neonatal outcomes. Cochrane Database Syst Rev. 2013;CD004074.
8. World Health Organization PAHO. Beyond Survival: Integrated Delivery Care Practices for Long-Term Maternal and Infant Nutrition, Health and Development; 2013.

9. World Health Organization. Delayed Clamping of the Umbilical Cord to Reduce Infant Anemia; 2013.

10. National Institute for Health and Care Excellence. Intrapartum Care for Healthy Women and Babies; 2014.

11. Perinatal Services BC. Provincial Perinatal Guidelines Standards for Neonatal Resuscitation; September, 2017.

12. Ceriani Cernadas JM, Carroli G, Pellegrini L, et al. The effect of timing of cord clamping on neonatal venous hematocrit values and clinical outcome at term: a randomized, controlled trial. Pediatrics. 2006;117:e779-86. doi:10.1542/peds.2005-1156

13. Bhutani VK, Johnson L, Sivieri EM. Predictive ability of a predischarge hour-specific serum bilirubin for subsequent significant hyperbilirubinemia in healthy term and near-term newborns. Pediatrics. 1999;103:6-14. doi:10.1542/peds.103.1.6

14. Bernard R. Fundamentals of Biostatistics. Vol. 2. Boston: PWS Publishers; 2000:140-246.

15. Garofalo M, Abenhaim HA. Early versus delayed cord clamping in term and preterm births: a review. J Obstet Gynaecol Can. 2012;34 (6):525-531. doi:10.1016/S1701-2163(16)35268-9

16. Mercer JS, Erickson-Owens DA, Collins J, Barcelos MO, Parker AB, Padbury JF. Effects of delayed cord clamping on residual placental blood volume, hemoglobin and bilirubin levels in term infants: a randomized controlled trial. $J$ Perinatol. 2016;00:1-5.

17. Mathew JL. Timing of umbilical cord clamping in term and preterm deliveries and infant and maternal outcomes: a systematic review of randomized controlled trials. Indian Pediatr. 2011;48(2):123-129. doi:10.1007/s13312-011-0031-z

18. Andersson O, Hellström-Westas L, Andersson D, Domellof M. Effect of delayed versus early umbilical cord clamping on neonatal outcomes and iron status at 4 months: a randomised controlled trial. $B M J$. 2011;343(nov15 1):d7157-d7157. doi:10.1136/bmj.d7157

19. Chaparro CM, Neufeld LM, Tena Alavez G, Eguia-Líz Cedillo R, Dewey,KG. Effect of timing of umbilical cord clamping on iron status in Mexican infants: a randomised controlled trial. Lancet. 2006;367(9527):1997-2004. doi:10.1016/S0140-6736(06)68889-2

20. Jahazi A, Kordi M, Mirbehbahani NB, Mazloom SR. The effect of early and late umbilical cord clamping on neonatal hematocrit. $J$ Perinatol. 2008;28(8):523-525. doi:10.1038/jp.2008.55

21. Purisch SE, Ananth CV, Arditi B, et al. Effect of delayed vs immediate umbilical cord clamping on maternal blood loss in term cesarean delivery: a randomized clinical trial. JAMA. 2019;322(19):18691876. doi:10.1001/jama.2019.15995

22. Viprakasit V. Approach to childhood anemia. J Hematol Transfus Med. 2014;24:395-405.

23. Emhamed MO, van Rheenen P, Brabin BJ. The early effects of delayed cord clamping in term infants born to Libyan mothers. Trop Doct. 2004;34:218-222. doi:10.1177/004947550403400410
The International Journal of Women's Health is an international, peerreviewed open-access journal publishing original research, reports, editorials, reviews and commentaries on all aspects of women's healthcare including gynecology, obstetrics, and breast cancer. The manuscript management system is completely online and includes a very quick and fair peer-review system, which is all easy to use. Visit http://www.dovepress.com/testimonials.php to read real quotes from published authors. 